\title{
New Azobenzene Chromophores as Monomers for Synthesis of Polyesters
}

\author{
Ewa Schab-BalcerzaK,$^{\dagger}$ Eugenia Grabiec, Danuta Ş̧K, and Andrzej Miniewicz* \\ Centre of Polymer Chemistry, Polish Academy of Sciences, 34 M. Curie-Skłodowska Str., 41-819 Zabrze, Poland \\ *Institute of Physical and Theoretical Chemistry, Wrockaw University of Technology, 50-370 Wrockaw, Poland
}

(Received January 23, 2003; Accepted August 5, 2003)

\begin{abstract}
Two new azo-chromophores: 2,4-dihydroxy-4'-nitroazobenzene and 2,4-dihydroxy-4-azo-(4'nitroazobenzeno)benzene have been prepared. These diols have been applied as monomers for polyesters synthesized in condensation with diacid chlorides: isophthaloyl chloride and sebacoyl chloride. The copolymers consist of mixture of two new diols and chlorides have been obtained as well. The polymers were identified by infrared and elemental analysis. Character of polymers was determined using X-ray spectroscopy. Thermal properties of polyesters such as glass transition temperature and thermal stability were investigated using differential scanning calorimetry (DSC) method and thermogravimetric analysis. These polymers with azobenzene groups could find potential applications as holographic recording materials. The preliminary investigations of optical grating recording were carried out.

KEY WORDS Polyesters / Chromophores / Azo Dye / Photoisomerization / Holographic Recording /
\end{abstract}

Azobenzene containing polymers are of special interests with respect to the reversibility of the photorearrangement, a number of interesting effects and potential applications. Such polymers in the form of solid films have been investigated for potential technological applications. It is intension to use this kind of polymers in such applications as optical information storage, optical information processing, aligning layers for liquid crystals, optical switching devices and diffractive optical elements among others. ${ }^{1}$

The use of polymeric materials for optical applications offers many advantages in comparison with the use of inorganic materials, among them being the low weight of the optical components, the good mechanical properties of polymers, and the ease of manufacturing technical parts. ${ }^{2}$

Many of optical applications are possible due to efficient photoisomerization and photoinduced processes such as photo-induced orientation resulting in anisotropic films or in light induced diffusion generating surface relief gratings (Scheme 1).

Azobenzene groups are known to exist in two isomeric states, a thermodynamically stable trans and a meta-stable cis form. When irradiated with light of appropriate wavelength, the azobenzene chromophores undergo a reversible trans $\Rightarrow c i s \Rightarrow$ trans photoisomerization process. Linearly polarized light causes a cooperative-orientation of the azobenzene moieties and other segments of the polymers perpendicular to the electric field vector of the incident light. This results in the induction of anisotropy in the films causing a birefringence and dichroism. ${ }^{1}$ This process can be used to

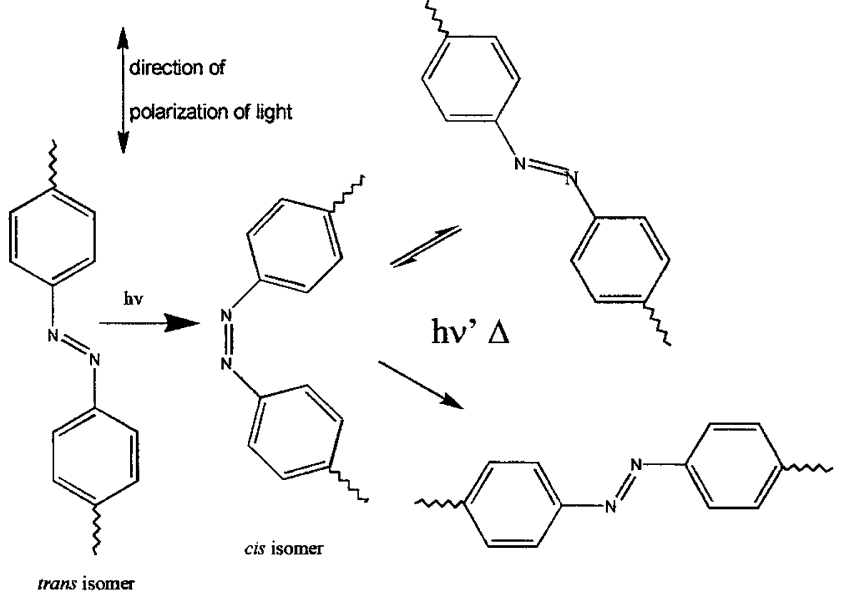

Scheme 1. Photoisomerization of azobenzene groups upon linearly polarized light and photoorientation.

generate erasable holographic gratings in the volume. On continued exposure the light driven diffusion process causes the formation of surface relief gratings in the same type of polymers.

So the amorphous azobenzene-containing polymers are able to reversibly store optical information. Holography is a technique for memorizing the amplitude and the phase of light, in which recording and reading of three-dimensional images is possible. It is expected that holography is the most promising technique for establishing photonics as a future technology?

The possibility of using such types of photochromic polymers for reversible optical storage, holographic or digital was first suggested in 1984. The real interest in the subject started in 1987, when Wendorff demonstrated reversible optical storage properties us-

${ }^{\dagger}$ To whom correspondence should be addressed (E-mail: ewabalce@server.cchp-pan.zabrze.pl). 
ing liquid-crystalline (LC) polymers. In spite of this that many papers on this field concerns LC polymers it was found that liquid crystallinity is not a necessary condition for a material to exhibit the reversible optical storage properties. ${ }^{4}$

From survey of the literature it appears that much effort has been devoted to the synthesis of functionalized azopolymers as a new class of holographic materials. ${ }^{5}$ The various strategies in the design and synthesis of such polymers have been applied. Especially interesting direction concerns synthesis of new compounds with photochromic groups, which can be treated as monomers. It is necessary to develop the new types of functionalized polymers in order to find compromises in the polymer compositions with respect to the requirements of the different applications. It was found that the optical response of the polymer is strongly influenced by its structure and the rate of achieving birefringence and the level of induced birefringence depend on the type and size of the azo group. ${ }^{6}$

Polyesters are a group of polymers, which are not so intensively investigated from the point of view of possibility of their application for holography.

In the present study, polyesters containing azobenzene group were prepared and resulting polymer properties, such as thermal stability, spectral properties, solubility were investigated. In this work we have focused our attention on the: diffraction power, recording time and diffraction efficiency in the one chosen polyester film.

\section{EXPERIMENTAL}

\section{Measurements}

Infrared (IR) spectra were recorded on a BIO-RAD FTS 40 A Spectrometer using KBr pellets. Proton nuclear magnetic resonance $\left({ }^{1} \mathrm{HNMR}\right)$ spectra were run on a Varian Inova 300 Spectrometer in DMSO- $d_{6}$ or $\mathrm{CDCl}_{3}$ using Tetramethylsilane (TMS) as the internal reference. Differential scanning calorimetry measurements were done using a TA DSC 2010 apparatus with a heating rate of $20^{\circ} \mathrm{C} \mathrm{min}^{-1}$ under nitrogen. UV spectra were recorded in $m$-cresol solution on BECKMAN Acta M-IV spectrophotometer within the $200-330 \mathrm{~nm}$ range. X-Rays diffractions patterns were performed at room temperature using a conventional $\theta-2 \theta$ diffractometer, using $\mathrm{Ni}$-filter $\mathrm{Cu}-\mathrm{K} \alpha \mathrm{X}$-Ray in the reflection mode. The holography grating was recorded using $514.5 \mathrm{~nm} \mathrm{Ar}^{+}$laser light. The gratings formed in the polymer film were monitored by measuring the power of the first order diffracted beam. The recording light power was $P_{\text {inc }}=12.5 \mathrm{~mW}$ and beam intersection angle $\theta=8.6^{\circ}$.

\section{Reagents}

Dimethylacetamid (DMA) and pyridine were purified by standard technique prior to use. Benzoyl chloride was distillated. Isophthaloyl chloride was crystallized from mixture of ethyl ether:cyclohexane:carbon tetrachloride, $1: 1: 1$.

Sebacoyl chloride (Aldrich) and Orange 3 (Aldrich) were used without purification.

\section{Synthesis of Monomers and Model Compounds}

Monomer 1: 2,4-Dihydroxy-4'-nitroazobenzene. To $10 \mathrm{mmol}(1.44 \mathrm{~g})$ of $p$-nitroaniline, $2.7 \mathrm{~mL}$ of concentrated hydrochloric acid and $10 \mathrm{~mL}$ of water were added to make its salt solution. The mixture was placed in an ice bath. To the cooled mixture a solution of $10 \mathrm{mmol}(0.7 \mathrm{~g})$ of sodium nitrite in $1.5 \mathrm{~mL}$ of water was added dropwise and was stirred at a temperature between 0 and $5^{\circ} \mathrm{C}$ during $15 \mathrm{~min}$. Then it was poured slowly into a solution containing $10 \mathrm{mmol}(1.1 \mathrm{~g})$ of resorcinol in $8 \mathrm{~mL}$ of methanol. The reaction was carried out for $30 \mathrm{~min}$ in ice bath and was neutralised with sodium acetate to $\mathrm{pH} 5-6$. After the temperature was raised to $20^{\circ} \mathrm{C}$ the mixture was stirred for $1 \mathrm{~h}$. The product was filtered, washed with water and dried in vacuum at $70^{\circ} \mathrm{C}(85,1 \%$ yield $)$.

${ }^{1} \mathrm{H}$ NMR (DMSO- $\left.d_{6}, \mathrm{ppm}\right): \delta=6.36(\mathrm{~d}, \mathrm{ArH}$, $1 \mathrm{H}), 6.50(\mathrm{~m}, \mathrm{ArH}, 1 \mathrm{H}), 7.67$ (d, ArH, $1 \mathrm{H}), 8.04$ (d, ArH, $2 \mathrm{H}), 8.35$ (d, ArH, $2 \mathrm{H}), 10.87(\mathrm{~s},-\mathrm{OH}, 1 \mathrm{H})$, $12.14(\mathrm{~s},-\mathrm{OH}, 1 \mathrm{H})$. FT-IR (KBr): $3280 \mathrm{~cm}^{-1}(\mathrm{~s}, \mathrm{OH})$, $1510 \mathrm{~cm}^{-1}$ and $1340 \mathrm{~cm}^{-1}\left(\mathrm{NO}_{2}\right)$. UV-Vis ( $m$-cresol): $\lambda_{\max }=460 \mathrm{~nm}$.

$\left(\mathrm{C}_{12} \mathrm{H}_{9} \mathrm{~N}_{3} \mathrm{O}_{4}\right)$ (259.22): Calcd. C $55.6 \mathrm{H} 3.50 \mathrm{~N}$ 16.21; Found C 55.33 H 3.57 N 16.30. Mp: 209$211^{\circ} \mathrm{C}$.

Monomer 2: 2,4-Dihydroxy-4-azo-(4'-nitroazobenzeno)benzene. To $10 \mathrm{mmol}$ (3.63 g) of Orange 3, $2.7 \mathrm{~mL}$ of concentrated hydrochloric acid and $10 \mathrm{~mL}$ of water were added and then the same preparation rout as for chromophores 1 was applied. The crude product was crystallized from methanol (65\% yield).

${ }^{1} \mathrm{H}$ NMR (DMSO- $\left.d_{6}, \mathrm{ppm}\right): \delta=6.38(\mathrm{~s} ; \mathrm{ArH}, 1 \mathrm{H})$, 6.46 (d; ArH, $1 \mathrm{H}), 7.71(\mathrm{~d}, \mathrm{ArH}, 1 \mathrm{H}), 8.10(\mathrm{~m} ; \mathrm{ArH}$, $4 \mathrm{H}), 8.43$ (d; ArH, $2 \mathrm{H}), 8.45$ (d; ArH, $2 \mathrm{H}), 10.77$ (s; $\mathrm{OH}, 1 \mathrm{H}), 12.31$ (s; OH, $1 \mathrm{H})$, FT-IR (KBr): $3300 \mathrm{~cm}^{-1}$ (s, OH), $1520 \mathrm{~cm}^{-1}$, and $1341 \mathrm{~cm}^{-1}\left(\mathrm{NO}_{2}\right)$. UV-Vis $(m-$ cresol): $\lambda_{\max }=506 \mathrm{~nm}$.

$\left(\mathrm{C}_{18} \mathrm{H}_{13} \mathrm{~N}_{5} \mathrm{O}_{4}\right)$ (363.3): Calcd. C $59.50 \mathrm{H} 3.61 \mathrm{~N}$ 19.28; Found C 59.18 H 3.60 N 18.81.

$D T$ (decomposition temperature $)=204^{\circ} \mathrm{C}$

Model compounds 3, 4. To a stirred solution of $1 \mathrm{mmol}(0.239 \mathrm{~g})$ of chromophore 1- model 3 (or $0.363 \mathrm{~g}$ of chromophore 2- model 4) and $2 \mathrm{mmol}$ $(0.15 \mathrm{~mL})$ of pyridine in $5 \mathrm{~mL}$ of DMA at room temper- 
ature, a solution of $4 \mathrm{mmol}(0.25 \mathrm{~mL})$ of benzoyl chloride in $2.5 \mathrm{~mL}$ of DMA was added dropwise for $10 \mathrm{~min}$. After $3 \mathrm{~h}$ of reaction in room temperature the mixture was heated to $80^{\circ} \mathrm{C}$ for $1 \mathrm{~h}$.

The reaction solution was poured into methanol and precipitated model compound was filtered and dried. Model 3 was crystallized from acetone while model compound 4 was washed with boiling methanol.

Model compound 3. ${ }^{1} \mathrm{HNMR}\left(\mathrm{CDCl}_{3}, \mathrm{ppm}\right): \delta=$ 8.43 (d, ArH, $2 \mathrm{H}), 8.21$ (d, ArH, $2 \mathrm{H}), 8.41$ (d, ArH, $1 \mathrm{H}), 6.96(\mathrm{dd}, \mathrm{ArH}, 1 \mathrm{H}), 7.08(\mathrm{~d}, \mathrm{ArH}, 1 \mathrm{H}), 7.72(\mathrm{~m}$, ArH, 2 H), 7.84 (d, ArH, 4 H), 7.62 (m, ArH, 4 H), FTIR (KBr): $1740 \mathrm{~cm}^{-1}$ (s, $\left.-\mathrm{O}-\mathrm{C}=\mathrm{O}\right), 1523 \mathrm{~cm}^{-1}$, and $1345 \mathrm{~cm}^{-1}\left(\mathrm{NO}_{2}\right)$. UV-Vis $\left(m\right.$-cresol): $\lambda_{\max }=344$, $466 \mathrm{~nm}$.

$\left(\mathrm{C}_{26} \mathrm{H}_{17} \mathrm{~N}_{3} \mathrm{O}_{6}\right)$ (467.18): Calcd. C $66.79 \mathrm{H} 3.67 \mathrm{~N}$ 8.99; Found C $66.47 \mathrm{H} 3.59 \mathrm{~N}$ 8.93. $\mathrm{Mp} 180^{\circ} \mathrm{C}$.

Model compound 4. ${ }^{1} \mathrm{HNMR}\left(\mathrm{CDCl}_{3}, \mathrm{ppm}\right): \delta=$ 8.38 (m, ArH, $1 \mathrm{H}), 8.30$ (m, ArH, $2 \mathrm{H}), 8.23$ (d, ArH, $2 \mathrm{H}), 8.0$ (m, ArH, $4 \mathrm{H}), 7.90$ (m, ArH, $4 \mathrm{H}), 7.69$ (m, ArH, $2 \mathrm{H}), 7.57$ (m, ArH, $4 \mathrm{H}), 7.41$ (d, ArH, $1 \mathrm{H}), 7.33$ (dd, ArH, $1 \mathrm{H})$, FT-IR (KBr): $1743 \mathrm{~cm}^{-1}(\mathrm{~s},-\mathrm{O}-\mathrm{C}=\mathrm{O})$, $1523 \mathrm{~cm}^{-1}$, and $1343 \mathrm{~cm}^{-1}\left(\mathrm{NO}_{2}\right)$. UV-Vis ( $m$-cresol): $\lambda_{\text {max }}=386,465 \mathrm{~nm}$.

$\left(\mathrm{C}_{32} \mathrm{H}_{21} \mathrm{~N}_{5} \mathrm{O}_{4}\right)(571.548)$ : Calcd. C $67.25 \mathrm{H} 3.70 \mathrm{~N}$ 12.25; Found C 66.53 H 3.62 N 13.16 .

$D T$ (decomposition temperature $)=190^{\circ} \mathrm{C}$

\section{Polymer Synthesis}

Polyesters 5a-b were prepared by condensation reaction of 1 with sebacoyl chloride and isophthaloyl chloride respectively, while polyesters $\mathbf{6} \mathbf{a}-\mathbf{b}$ were prepared by condensation reaction of $\mathbf{2}$ with the same dichlorides. Copolyesters $\mathbf{7 a}-\mathbf{b}$ were prepared by reaction of mixture 1 and 2 (50:50) with sebacoyl chloride or isophthaloyl chloride. A typical polycondensation procedure was as follows. To a stirred solution of $1 \mathrm{mmol}$ of diol-chromophore and $2 \mathrm{mmol}$ of pyridine in $5 \mathrm{~mL}$ of DMA a solution of $1 \mathrm{mmol}$ of diacid chloride (sebacoyl chloride or isophthaloyl chloride) in $2.5 \mathrm{~mL}$ of DMA, was added dropwise for $10 \mathrm{~min}$. The solution was stirred at room temperature for $24 \mathrm{~h}$. Then it was heated to $90^{\circ} \mathrm{C}$ for $1 \mathrm{~h}$. The polymer was precipitated into methanol and collected by filtration. Then the polyester was washed with methanol in a Soxhlet extractor and was dried at $50^{\circ} \mathrm{C}$. Elemental analyses of polymers $\mathbf{5 a}-\mathbf{b}, \mathbf{6} \mathbf{a}-\mathbf{b}$, and $\mathbf{7 a}-\mathbf{b}$ are listed in Table I.

\section{RESULT AND DISCUSSION}

In this paper, the synthesis and characterization of polyesters obtained from a new monomer containing azobenzene group is reported.
Table I. Elemental analysis of polymers 5, 6, and 7

\begin{tabular}{|c|c|c|c|c|}
\hline \multirow{2}{*}{ polymer } & \multirow{2}{*}{$\begin{array}{c}\text { Repeating units } \\
\text { formulae } \\
\text { (Formula weight) }\end{array}$} & \multicolumn{3}{|c|}{ Elemental analysis; Calc. (Found) } \\
\hline & & $\mathrm{C} \%$ & $\mathrm{H} \%$ & N\% \\
\hline $5 \mathbf{a}$ & $\begin{array}{c}\mathrm{C}_{20} \mathrm{H}_{11} \mathrm{~N}_{3} \mathrm{O}_{6} \\
(389.323)\end{array}$ & $\begin{array}{c}61.90 \\
(60.31)\end{array}$ & $\begin{array}{c}3.15 \\
(3.15)\end{array}$ & $\begin{array}{c}10.96 \\
(10.93)\end{array}$ \\
\hline $5 \mathbf{b}$ & $\begin{array}{c}\mathrm{C}_{26} \mathrm{H}_{17} \mathrm{~N}_{3} \mathrm{O}_{6} \\
(467.177)\end{array}$ & $\begin{array}{c}62.14 \\
(61.66)\end{array}$ & $\begin{array}{c}5.40 \\
(5.55)\end{array}$ & $\begin{array}{c}9.88 \\
(9.78)\end{array}$ \\
\hline $6 \mathbf{a}$ & $\begin{array}{c}\mathrm{C}_{26} \mathrm{H}_{15} \mathrm{~N}_{5} \mathrm{O}_{6} \\
(493.434)\end{array}$ & $\begin{array}{c}63.29 \\
(59.74)\end{array}$ & $\begin{array}{c}3.06 \\
(3.34)\end{array}$ & $\begin{array}{c}14.19 \\
(15.14)\end{array}$ \\
\hline $6 \mathbf{b}$ & $\begin{array}{c}\mathrm{C}_{28} \mathrm{H}_{27} \mathrm{~N}_{5} \mathrm{O}_{6} \\
(529.551)\end{array}$ & $\begin{array}{c}63.51 \\
(61.41)\end{array}$ & $\begin{array}{c}5.14 \\
(4.90)\end{array}$ & $\begin{array}{c}13.23 \\
(14.70)\end{array}$ \\
\hline $7 \mathbf{a}$ & $\begin{array}{c}\mathrm{C}_{39} \mathrm{H}_{22} \mathrm{~N}_{8} \mathrm{O}_{11} \\
(778.650)\end{array}$ & $\begin{array}{c}60.16 \\
(59.76)\end{array}$ & $\begin{array}{l}2.85 \\
(3.34)\end{array}$ & $\begin{array}{c}14.39 \\
(15.61)\end{array}$ \\
\hline $7 b$ & $\begin{array}{c}\mathrm{C}_{41} \mathrm{H}_{34} \mathrm{~N}_{8} \mathrm{O}_{11} \\
(814.767)\end{array}$ & $\begin{array}{c}60.44 \\
(60.69)\end{array}$ & $\begin{array}{c}4.21 \\
(4.89)\end{array}$ & $\begin{array}{c}13.75 \\
(14.24)\end{array}$ \\
\hline
\end{tabular}

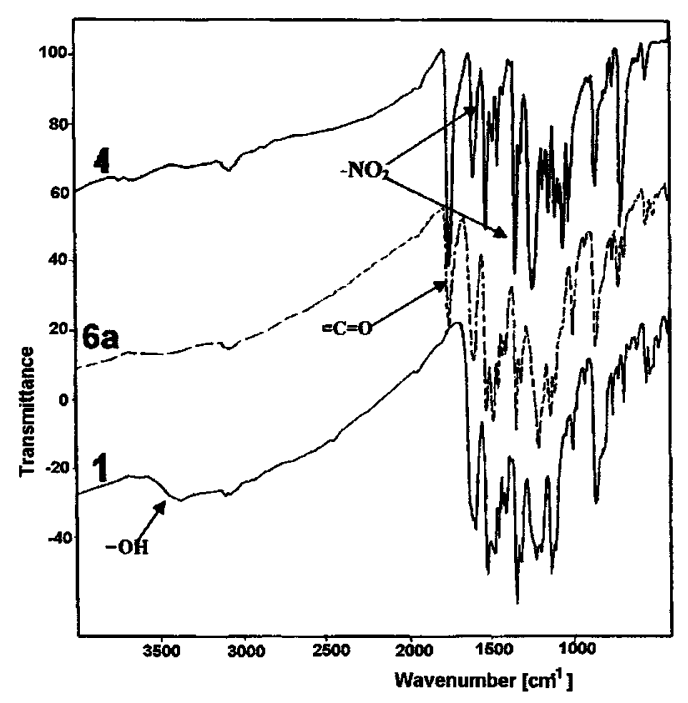

Figure 1. FT-IR spectra of compounds 2, 4, and polymer $\mathbf{6 a}$.

Monomers 1, 2, and model compounds 3, 4 were synthesized according to Scheme 2 and were characterized by elemental analysis, FT-IR, ${ }^{1} \mathrm{H}$ NMR and UV-vis spectroscopy and the results are in accordance with the proposed structures. In FT-IR spectra of the monomers absorption band at about $3280 \mathrm{~cm}^{-1}$ characteristic for phenyl hydroxy group, $1510 \mathrm{~cm}^{-1}$ and $1340 \mathrm{~cm}^{-1}$ characteristic for the $\mathrm{NO}_{2}$ group were detected (Figure 1). In case of the model compounds characteristic absorption appeared at $1740 \mathrm{~cm}^{-1}$ due to carbonyl stretching vibration in ester group and absorption bands due to the $\mathrm{NO}_{2}$ group are present. In ${ }^{1} \mathrm{H}$ NMR spectrum of monomers 1, 2 two peaks characteristic for hydrogen atom in phenol group are observed. The phenomenon that protons of the two hydroxylic groups bonded with phenyl ring at different position gives two peaks can be explained by possibility of creation of chelate bonds. Such chelate ring can be formed between nitrogen of azo group and hydrogen of $-\mathrm{OH}$ group placed in $o$ position. In this way two different signals of protons 

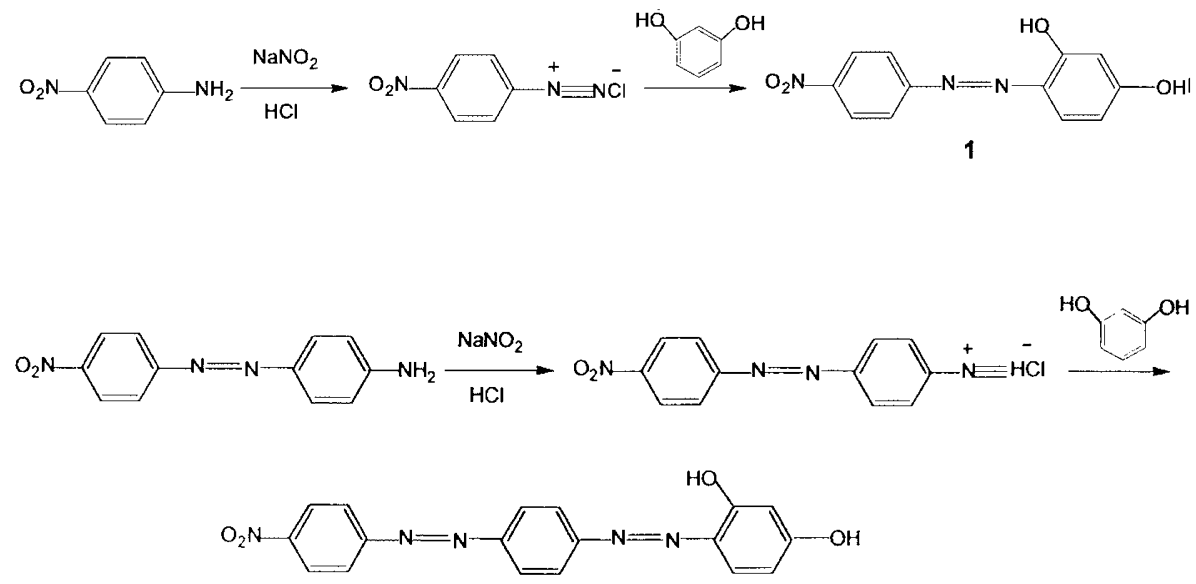

2

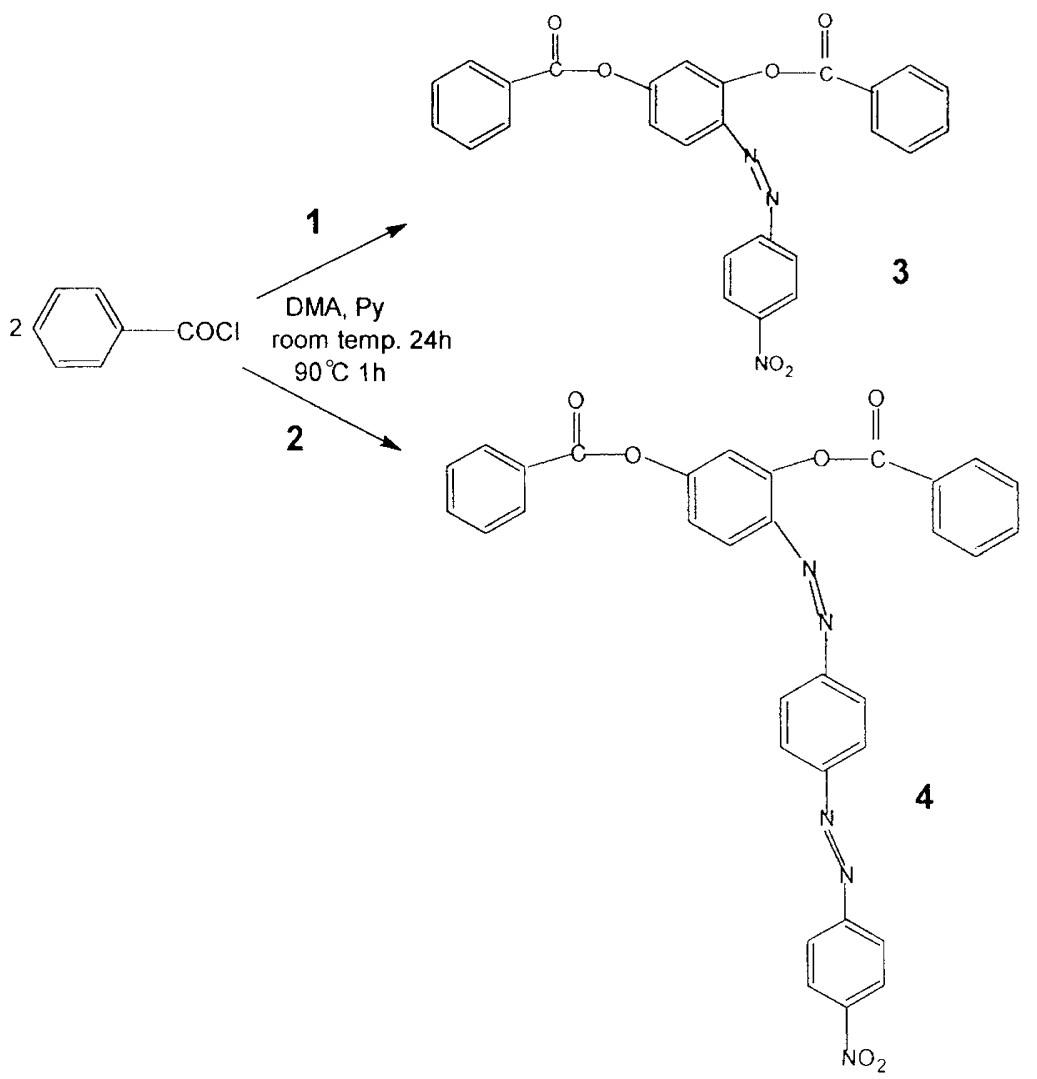

Scheme 2.

can be observed in the moiety of azo-diols.

Structures of the polyesters presented on Scheme 3 were confirmed by FT-IR spectroscopy (Figure 1). All the polymers showed characteristic absorption bands $\left(1740,1510,1340 \mathrm{~cm}^{-1}\right.$ and lack of absorption band at $3280 \mathrm{~cm}^{-1}$ of OH group) being in good agreement with model compounds. Elemental analyses of polymers are presented in Table I.

The polymers exhibited some ordered regions as determined by X-ray powder diffraction pattern (Figure 2). In Table III are listed the observed $d$ spacings, intensities and position of the reflection peaks for $\mathbf{5 a}-\mathbf{b}$ and $\mathbf{6 a - b}$. The reflection peaks at about $16(2 \theta)$ are connected with main chain of polymers and for $\mathbf{6 a}$ and $\mathbf{5 a}$ it can be seen the lack of influence of backbone chain (structure of chromophore) on character of the spectra in this region. But some differences are observed in the region of higher values of $2 \theta$. In spectrum of polymer 6a followings peaks are detected: 24.7, 26.6, $27.7(2 \theta)$ being characteristic for backbone chain, while for $\mathbf{5 a}$ only one at $25.6(2 \theta)$ is present. The longer backbone in $\mathbf{6} \mathbf{a}$ in comparison with the $\mathbf{5 a}$ is probably a reason of more ordered structure of polymer $\mathbf{6 a}$ and in this case three peaks are observed. Taking into consideration the polymers $\mathbf{6} \mathbf{b}$ and $\mathbf{5 b}$ it can be noted that the main chain of these polymers is more flexible than $\mathbf{6 a}$ and $\mathbf{5 a}$ and because of it is more susceptible to influence of backbone chain. This is probably reason that the peak con- 


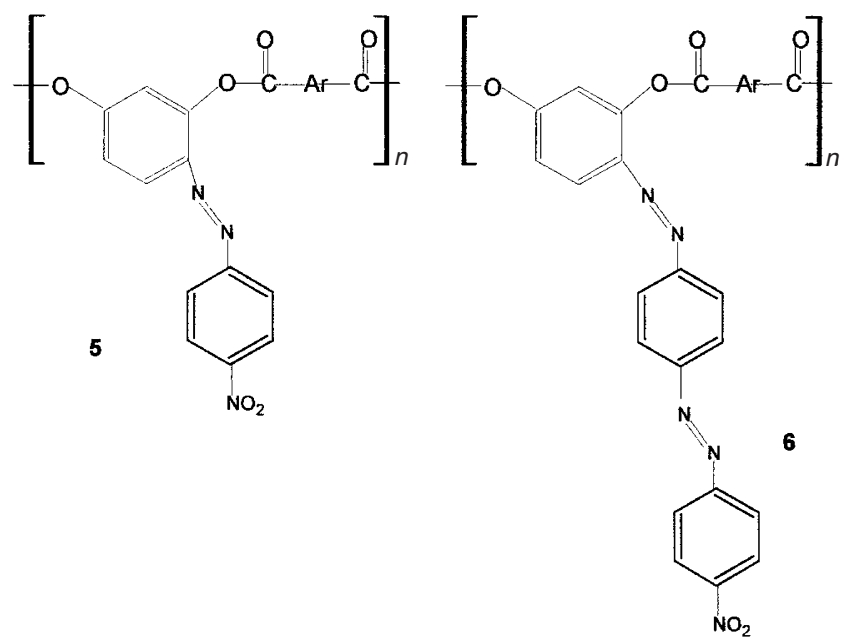

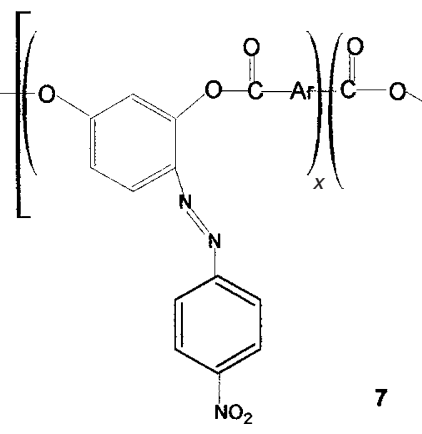

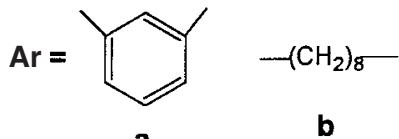

Scheme 3.

nected with the main chain for $\mathbf{6 a}$ is observed at 16.4 while for $\mathbf{5 a}$ at $19.7(2 \theta)$.

The presence of crystalline regions in polyesters was observed on DSC thermograms as well. In spite of glass transition temperature, the melting endotherm (at higher temperature than $T_{\mathrm{g}}$ ) of ordered part of the polymer was observed on DSC spectra. The melting point of polymers $\mathbf{5 a}, \mathbf{5 b}$, and $\mathbf{6} \mathbf{b}$ was detected at following temperatures: $230{ }^{\circ} \mathrm{C}, 79^{\circ} \mathrm{C}$, and $111^{\circ} \mathrm{C}$ respectively. The melting enthalpy was in the range of 13.0 $1.0 \mathrm{~J} \mathrm{~g}^{-1}$.

The thermal behaviour of the synthesised polyesters was evaluated by thermogravimetric analysis. The TG curves of all polymers showed two stages of weight loss (Figure 3). First one is connected with the decomposition of chromophores in polymer chain. ${ }^{8}$ In DSC spectra an exotherm peak observed at about $250^{\circ} \mathrm{C}$ probably corresponds to decomposition of nitro group. Initial decomposition temperature (IDT) is in the similar region of temperature between $230-220^{\circ} \mathrm{C}$ for all

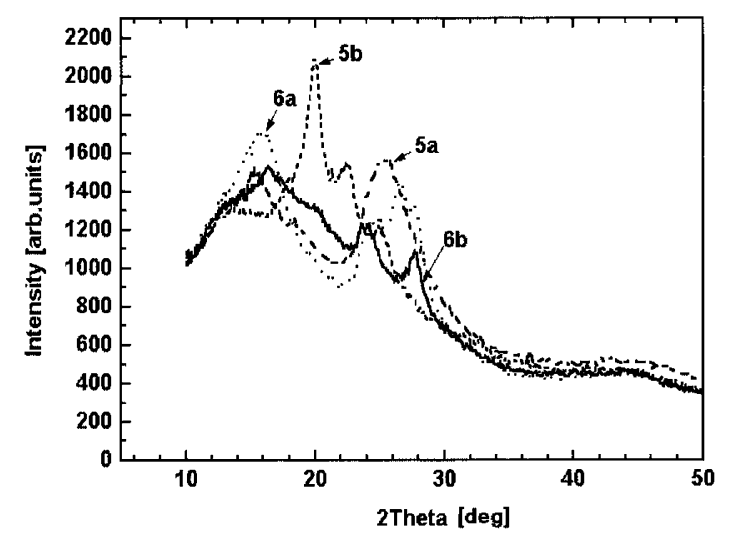

Figure 2. X-Ray powder diffraction profile of polymers $\mathbf{5 a - b}$ and $\mathbf{6 a}-\mathbf{b}$.

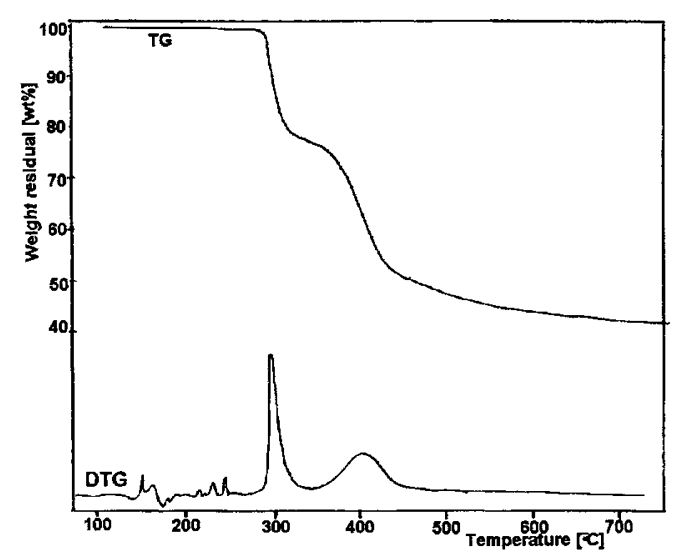

Figure 3. Thermogravimetric analysis of polymer $\mathbf{5 b}$.

Table II. Glass transition temperature and thermal stability of the polyesters

\begin{tabular}{crrrrccc}
\hline \multirow{2}{*}{ Polymer } & \multicolumn{1}{c}{$T_{\mathrm{g}}$} & $I D T^{\mathrm{a}}$ & \multicolumn{4}{c}{ Temperatures for \% weight loss $\left[{ }^{\circ} \mathrm{C}\right]$} \\
\cline { 5 - 7 } & {$\left[{ }^{\circ} \mathrm{C}\right]$} & {$\left[{ }^{\circ} \mathrm{C}\right]$} & 5 & 10 & $\begin{array}{c}\text { Beginning of } \\
\text { second step } \\
\text { decomposition }\end{array}$ & $\begin{array}{c}\text { Residue at } \\
1000^{\circ} \mathrm{C} \\
{[\%]}\end{array}$ \\
\hline $\mathbf{5 a}$ & 148 & 210 & 295 & 315 & 410 & 50 \\
$\mathbf{5 b}$ & 53 & 220 & 290 & 300 & 350 & 42 \\
$\mathbf{6 a}$ & 150 & 230 & 290 & 330 & 420 & 66 \\
$\mathbf{6 b}$ & 79 & 220 & 270 & 280 & 360 & 47 \\
$\mathbf{7 a}$ & 134 & 220 & 260 & 310 & 430 & 57 \\
$\mathbf{7 b}$ & 62 & 230 & 260 & 280 & 340 & 56 \\
\hline
\end{tabular}

${ }^{\mathrm{a}} I D T$ : initial decomposition temperature.

polymers. Thermal properties of polymers are summarised in Table II. These polyesters lost $10 \%$ of weight in the range of $280-330^{\circ} \mathrm{C}$. Taking into consideration this temperature, the following order can be given with respect to the temperature of $10 \%$ weight loss of polyesters: $\mathbf{6 a}>\mathbf{5 a}>\mathbf{7 a}>\mathbf{5 b}>\mathbf{6 b}=\mathbf{7 b}$. The similar dependence was observed in case of the residue at $1000^{\circ} \mathrm{C}$. The residue at $1000^{\circ} \mathrm{C}$ of polymers was in the range of $66-42 \%$. Higher thermal stability exhibited polymers synthesised from isophthaloyl chloride (5a, 6a, and 7a). Taking into account the presence in polymers diols with one azobenzene or 
Table III. X-Ray diffraction date for the polyesters

\begin{tabular}{cccc}
\hline \multirow{2}{*}{ Polymer } & $\begin{array}{c}\text { Peak position } \\
\text { Angle } \\
\left.2 \theta{ }^{\circ}\right]\end{array}$ & $\begin{array}{c}\text { Bragg distance-d } \\
{[\AA]}\end{array}$ & $\begin{array}{c}\text { Intensity } \\
\text { [arb.units] }\end{array}$ \\
\hline \multirow{2}{*}{$\mathbf{5 a}$} & 15.25 & 5.81 & 1500.5 \\
& 25.60 & 3.48 & 1554.2 \\
& & & \\
& 15.98 & 5.54 & 1713.1 \\
$\mathbf{6 a}$ & 24.73 & 3.60 & 1240.0 \\
& 26.63 & 3.35 & 1436.3 \\
& 27.50 & 3.24 & 1324.1 \\
& & & \\
$\mathbf{5 b}$ & 16.42 & 5.40 & 1529.7 \\
& 23.75 & 3.74 & 1206.2 \\
& 27.88 & 3.20 & 1077.0 \\
& & & \\
& 13.50 & 6.55 & 1332.8 \\
$\mathbf{6 b}$ & 19.77 & 4.49 & 2013.0 \\
& 22.40 & 3.97 & 1552.7 \\
& 25.02 & 3.56 & 1208.0 \\
\hline
\end{tabular}

Table IV. UV date of monomers 1, 2, model compounds 3, 4, and polymers

\begin{tabular}{ccccc}
\hline No & $\begin{array}{c}\lambda_{\max } \\
{[\mathrm{nm}]}\end{array}$ & $\begin{array}{c}\varepsilon \\
{\left[1 \mathrm{~mol}^{-1} \mathrm{~cm}\right]}\end{array}$ & $\begin{array}{c}\lambda_{\max } \\
{[\mathrm{nm}]}\end{array}$ & $\begin{array}{c}\varepsilon \\
{\left[1 \mathrm{~mol}^{-1} \mathrm{~cm}\right]}\end{array}$ \\
\hline $\mathbf{1}$ & - & - & 460 & 36000 \\
$\mathbf{3}^{*}$ & 344 & 10800 & 466 & 476 \\
$\mathbf{5 a}^{*}$ & 350 & 2300 & 465 & 500 \\
$\mathbf{5 b}^{*}$ & 347 & 12000 & 466 & 800 \\
& \multicolumn{5}{c}{} & & \\
$\mathbf{2}$ & - & - & 506 & 46000 \\
$\mathbf{4}$ & 386 & 39000 & 465 & 7000 \\
$\mathbf{6 a}$ & 397 & 17000 & 499 & 25000 \\
$\mathbf{6 b}$ & 340 & 31000 & 486 & 23000 \\
& & & & \\
$7 \mathbf{7}$ & 404 & 12000 & 468 & 13000 \\
$7 \mathbf{7 b}$ & 380 & 28000 & 468 & 24000 \\
\hline$m$-cresol $\mathrm{c}=1 \times 10^{-5}[\mathrm{~mol} / 1]$ & ${ }^{*} \mathrm{c}=1 \times 10^{-4}[\mathrm{~mol} / 1]$
\end{tabular}

two azobenzene groups no significant influence on thermal stability of polyesters was detected. On the other hand the polymers with two azobenzene groups showed slightly higher glass transition temperature than prepared from diol with single one. Glass transition temperature of polyesters synthesised from sebacoyl chloride was in the range of $53-79^{\circ} \mathrm{C}$, prepared from isophthaloyl chloride in the range of $150-134^{\circ} \mathrm{C}$.

The polymers and monomers were investigated by UV-vis spectroscopy and the received data are listed in Table IV. The UV-vis spectra of polymers showed two absorption maxima contrary to the spectra of monomers-chromophores, in which only one absorption band is observed (at 460 or $506 \mathrm{~nm}$ ). In case of chromophore 2 the absorption maximum is batochromic shifted in comparison with the maximum of

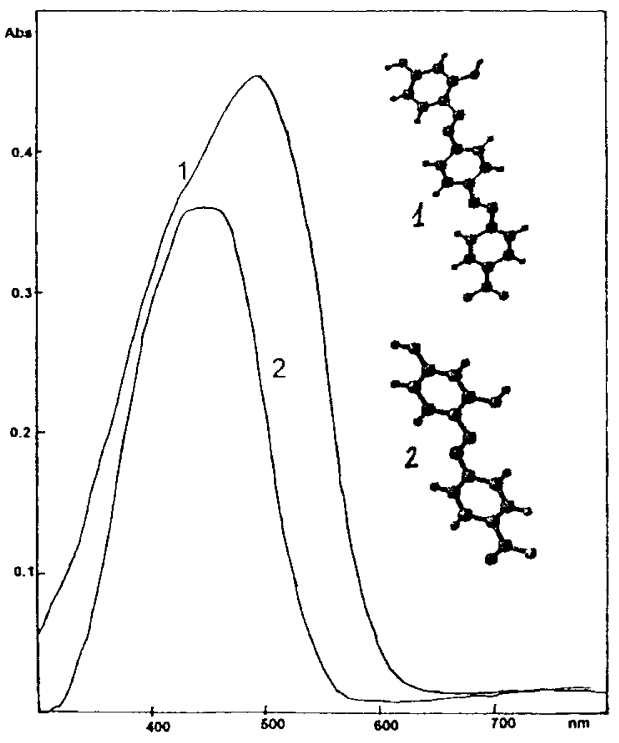

(a)

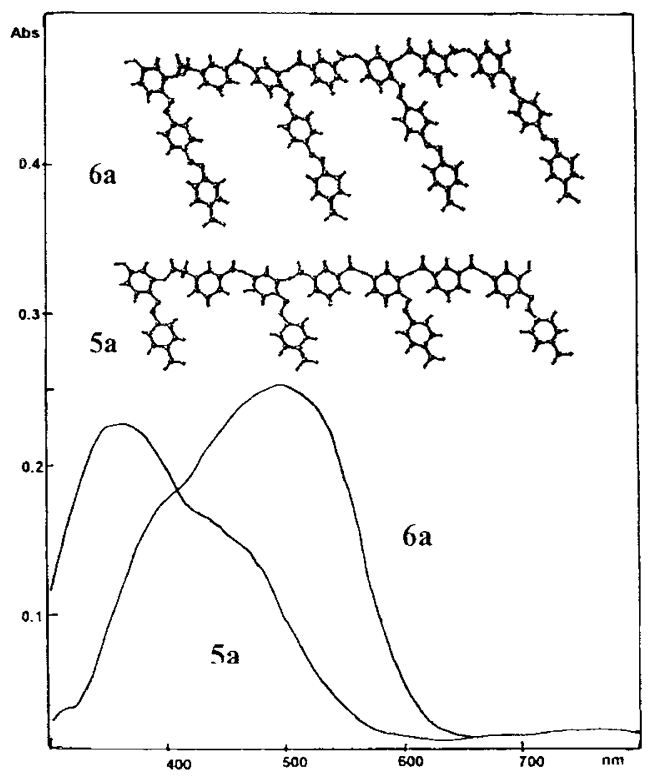

(b)

Figure 4. Ultraviolet spectra of (a) chromophore 1 and 2 (b) polymer $\mathbf{5 a}$ and $\mathbf{6 a}$.

1, at about $40 \mathrm{~nm}$ (Figure 4a). The same dependence was found in UV spectra of polymers in which the absorption band around 460-499 is characteristic for azo group. Polymers prepared from 1 exhibited hipsochromic shift in accordance to synthesised from $\mathbf{2}$ (Figure 4b). It was found that absorption band connected with azo group is stronger for polyesters obtained from chromophore with two azo 2 groups. Second absorption peak observed in UV-vis spectra of polymers being in the range of $347-397 \mathrm{~nm}$, was also red shifted for polyesters synthesised form monomer $\mathbf{2}$ in comparison to the polymers from monomer 1 . The influence of structure of the polymer main chain on intensity of UV absorption was detected as well. Polymers with aliphatic chain shown much higher absorp- 


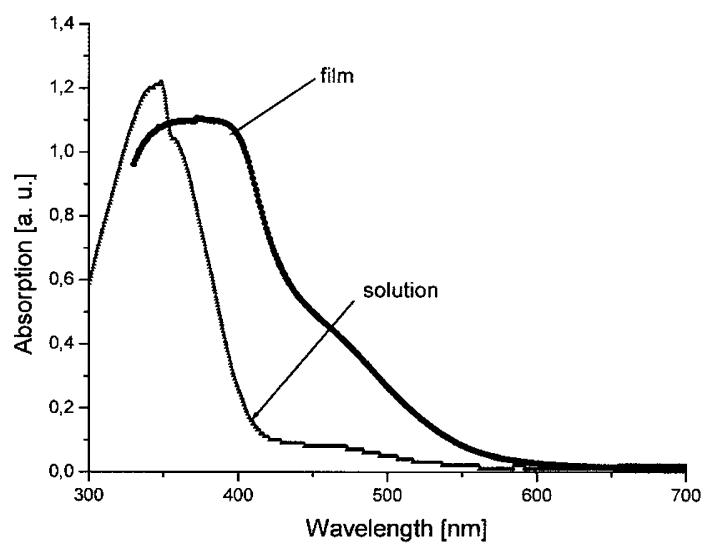

Figure 5. Comparison of the absorption spectra of polyester $\mathbf{5 b}$ in $m$-cresol solution and as film.

tion band in the shorter wavelength in comparison with polymers, which contain aromatic structure in the main chain.

The solubility of synthesised polymers in various solvents was investigated. These polymers except for polymer 5a were only partially soluble in aprotic dipolar solvents (1-Methyl-2-pyrrolidinone (NMP), $N, N$ Dimethylformamide (DMF), and DMA). All polyesters were soluble in $m$-cresol and $p$-chlorophenol. The ability of these polymers to film formation was investigated. The synthesised polyesters do not form freestanding films but in most cases they give optically good quality coating on glass plate.

\section{Optical Grating Recording Experiments}

Holographic grating recording experiments were carried out in film prepared from polyester $\mathbf{5 b}$. In Figure 5 are shown the absorption spectra of polymer film on glass plate and polymer in $m$-cresol solution. Films were casted from $p$-chlorophenol solution. They exhibit a light absorption peak at the wavelength of about $380 \mathrm{~nm}$.

Kinetics of holographic grating recording in polyester film 5b was studied using a standard twowave mixing technique. ${ }^{9}$ Diffraction gratings were recorded in two cases: when two incoming beams $I_{1}$ and $I_{2}$ were linearly polarised with electric field vectors perpendicular to the incidence plane - so called ss-polarisation (also VV) and second case when two beams were orthogonaly polarised with respect to each other-so called sp-polarisation (VH). In the first case, the phase variation between the beams intersecting at $\theta$ angle produces intensity fringe pattern of the form:

$$
I(\mathrm{x})=I_{0}(1+m \cos (K \mathrm{x}))
$$

Where $I_{0}=I_{1}+I_{2}$ is the sum of the incident beam intensities, $m$ is the modulation factor $m=2 \sqrt{I_{1} I_{2}} /\left(I_{1}+I_{2}\right)$, and $K=2 \pi / \Lambda$ the grating wave-vector with grating spacing $\Lambda=\lambda / 2 \sin (\theta / 2)$. In the case of VH polarisa-

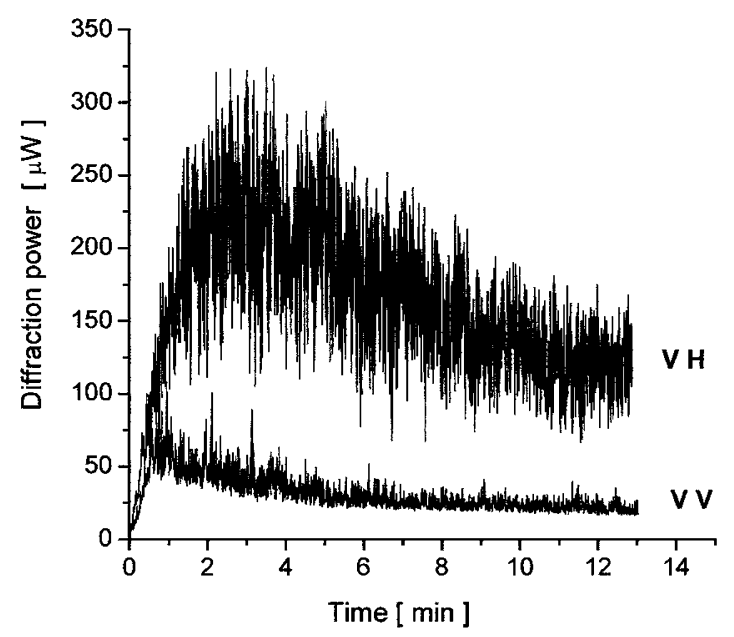

Figure 6. Time dependence of the first-order diffraction power for polyester $\mathbf{5 b}$ film recorded with $\mathrm{Ar}^{+}$laser at $514.5 \mathrm{~nm}$ for $\mathrm{VV}$ and $\mathrm{VH}$ configuration, $\Lambda=5.8 \mu \mathrm{m}$.

tion there is no modulation of light within intersection region and $I(\mathrm{x})=I_{0}=$ constant. In both cases $(\mathrm{VV}$ and $\mathrm{VH}$ ) of polarisation geometry a periodic birefringence and/or dichroism is induced. This results in a diffraction grating build-up as is evidenced by an appearance of self-diffraction. By monitoring the first order diffracted beam's power we could study the kinetics of grating formation. This is shown for VV and VH polarisations in Figure 6. As can be seen form the plot in Figure 6, using the same beam intensities, the grating of the type $\mathrm{VH}$ (i.e., polarisation grating) gives stronger diffraction than the VV one. Initially, the dynamics of the VV type grating build-up is faster than the VH. This behaviour could be explained by the difference in local light intensities in the two cases. This local light intensity in the case of $\mathrm{VV}$ grating recording is usually (for $I_{1}=I_{2}$ ) two times lager. The noise superimposed over the signal comes from the micromechanical instabilities of our optical setup. In the case of $\mathrm{VH}$ recording the momentarily mismatch between interference and already recorded diffraction patterns leads to energy transfer between the beams.

The square root of diffraction power temporal evolution can be fitted by the mono-exponential function:

$$
\sqrt{P_{\text {diff }}(t)}=\sqrt{P_{\text {diff }}^{\infty}}\left[1-A_{1} \exp \left(-\frac{t}{\tau_{1}}\right)\right]
$$

where $\sqrt{P_{\text {diff }}^{\infty}}$ is the saturation value of diffracted power, $\tau_{1}$ is a time constant of the process of the grating build-up. Fitting of both dependencies measured for $\mathrm{VV}$ and $\mathrm{VH}$ polarisation geometries according to eq 2 gives the following results: for $\mathrm{VV}$ polarisation $\tau_{1}=17 \mathrm{~s}, A_{1}=8.318$ and for $\mathrm{VH}$ polarisation $\tau_{1}=37 \mathrm{~s}$ and $A_{1}=12.897$.

The maximum of diffraction efficiency in the measured film were evaluated to amount $\eta_{\mathrm{VV}} \approx 0.55 \%$ and 
$\eta_{\mathrm{VH}} \approx 1.74 \%$.

Several orders of self-diffraction (up to fifth order) were observed that means that the Raman-Nath ${ }^{9}$ (i.e., thin grating regime) diffraction process is applicable. The decay of the grating after reaching the maximum amplitude could be explained by the process of a formation of a slanted gratings, i.e., a partial erasure of the grating due to shift of interference pattern versus already written gratings. We should stress than in this material the gratings have mixed phase $(\Delta n)$ and amplitude $(\Delta \alpha)$ character and the possibility of the relief grating formation is highly probable.

\section{REFERENCES}

1. N. K. Viswanathan, D. Y. Kim, S. Bian, J. Williams, W. Liu, L. Li, L. Samuelson, J. Kumar, and S. K. Tripathy, J. Mater.
Chem., 9, 1941 (1999).

2. M. Eich and J. H. Wendorff, Macromol. Chem. Rapid Commun., 8, 467 (1987).

3. T. Yamamoto, A. Ohashi, S. Yoneyama, M. Hasegawa, O. Tsutsumi, A. Kanazawa, T. Shiono, and T. Ikeda, J. Phys. Chem. B, 105, 2308 (2001).

4. A. Natansohn, P. Rochon, J. Gosselin, and S. Xie, Macromolecules, 25, 2268 (1992).

5. F. L. Labarthet, T. Buffeteau, and C. Sourisseau, J. Phys. Chem. B, 103, 6690 (1999).

6. M. Ahlheim and F. Lehr, Macromol. Chem. Phys., 195, 361 (1994).

7. G. O. Dudek and E. P. Dudek, J. Am. Chem. Soc., 88, 2407 (1966).

8. X. Meng, A. Natansohn, and P. Rochon, J. Polym. Sci., Part B: Polym. Phys., 34, 1461 (1996).

9. H. J. Eichler, P. Gunter, and D. Pohl, "Laser-Induced Dynamic Gratings”, Springer-Verlag GmbH \& Co., Berlin, 1986. 